\title{
GUACAMAYA: SÍMBOLO DE TEMPORALIDAD Y FERTILIDAD EN DOS EJEMPLOS DE PINTURA MURAL
}

\author{
María de Lourdes Navarijo Ornelas \\ Instituto de Biología \\ Universidad Nacional Autónoma de México
}

Resumen: En el pensamiento prehispánico, la guacamaya (Ara macao y Ara militaris) ocupó un lugar preferente, como lo atestigua su imagen plasmada en los murales creados por diferentes pueblos, como el maya, el zapoteca, el teotihuacano, o como se ve en Cacaxtla. Esto no es una coincidencia, por lo que este estudio tiene por objeto analizar y reconocer la identidad taxonómica de los individuos recreados, además de argumentar su presencia en el lenguaje pictórico como un medio de expresión gráfica irrefutable. Para este fin se trabaja con la pintura mural de dos sitios arqueológicos: el mural 1, Los pájaros, de la Estructura 86 en Xelhá, situado en la zona norte de Quintana Roo; y el mural oriente del Templo Rojo en Cacaxtla, Tlaxcala. De acuerdo con las modalidades de representación gráfica y bajo los criterios de integración temática se aborda la lectura de las escenas considerando a los otros elementos iconográficos que las integran. El resultado es una propuesta de participación simbólica de las guacamayas enfocada en la abstracción del tiempo a partir de la conducta diaria y estacional de esta especie de psitácido ruidosa (y de plumaje llamativo y sugerente); también se considera la asociación de estos animales con los conceptos de vida, movimiento y temporalidad, y con el Sol y el agua (este último como el elemento primordial vinculado con la fertilidad).

Palabras Clave: pintura mural, guacamaya, temporalidad, fertilidad, simbolismo.

AвSTRACT: In pre-Hispanic thought, Macaw (Ara macao and Ara militaris) occupy a place of honour, as witness its image captured in the murals created by different peoples, such as the Maya, the Zapotec, the ancient inhabitants of Teotihuacan and Cacaxtla. This is not a coincidence, which is why this study aims to analyze and recognize the taxonomic identity of recreated individuals, as well as argue their presence in the pictorial language as a mean of irrefutable graphic expression. To this end works with mural paintings from two archaeological sites are analyzed: the mural 1 "The birds" of the 86 structure at Xelhá, located in the northern part of Quintana Roo, and the wall East of the Red Temple in Cacaxtla, Tlaxcala, are studied. According to the modalities of graphic representation and under the criteria of thematic integration addresses the reading of the scenes taking into acount other iconographic elements that make them up. The result is a proposal for a token participation of the macaws on the abstraction of time from the daily and seasonal behavior of this kind of noisy psitacid and suggestive and striking plumage and its association with the concept of life, movement and temporality, in addition to its association with the Sun and water as the primary element linked to fertility.

KeYwoRDs: painting mural, macaw, temporality, fertility, symbolism.

RECEPCIÓN: 10 de febrero del 2011.

ACEPTACIÓN: 28 de junio del 2011. 



\title{
GUACAMAYA: SÍMBOLO DE TEMPORALIDAD Y FERTILIDAD EN DOS EJEMPLOS DE PINTURA MURAL
}

\author{
María de Lourdes Navarijo Ornelas \\ Instituto de Biología \\ Universidad Nacional Autónoma de México
}

\section{Introducción}

El ambiente natural constituye sin duda el escenario primigenio de cualquier civilización, el cual no sólo crea el contexto para que se desarrolle la cultura, sino que también establece la acción en ese hábitat delimitado para el surgimiento y consolidación de las diferentes estrategias implementadas para sobrevivir y prosperar (Herskovits, 1995: 173). Como parte de esas estrategias de vida, los primeros contactos que se dieron con los animales se explican por la necesidad de utilizarlos, de manera fundamental, como fuente de alimento y como materias primas para fines diversos. Con el paso del tiempo los variados usos materiales coevolucionan a partir de la apreciación de las cualidades físicas y conductuales de los animales, lo cual converge en un proceso de valoración circunstancial que se agrega al valor intrínseco y se incorpora y trasciende en el pensamiento de todos los pueblos por medio de modelos de conceptualización y significación de la naturaleza.

Sobre este mismo esquema de ideas, Broda (1991: 461-462) ha señalado que en el México prehispánico el culto tenía una estrecha relación con la observación de la naturaleza. Y fue gracias a esas observaciones metódicas que progresaron las matemáticas, la arquitectura, la astronomía, la medicina, la botánica y la zoología como un cuerpo de conocimientos exactos sobre los fenómenos naturales. Se debe tener en cuenta que la observación sistemática y repetida de estos fenómenos en el transcurso de los años influye en la construcción de la cosmovisión mezclándose con elementos míticos.

De acuerdo con los planteamientos de Broda (1991: 462), los vínculos con la naturaleza se manifiestan de tres formas básicas, esto es, por medio de la astronomía bajo la observación del curso del Sol, de la Luna, de las estrellas y de las constelaciones; la relación con los fenómenos climatológicos se rige de manera principal por las estaciones del año, pero de modo particular por la época de lluvias y por la estación de secas; y, por último, la relación que se mantiene con la naturaleza se hace evidente cuando se establecen los ciclos agrícolas.

Los testimonios de esta relación innata y esencial con la naturaleza son ciertamente heterogéneos, como lo demuestra el uso y la valoración que ha existido 
desde época inmemorial de las distintas especies de aves. En el caso particular de las guacamayas y los loros, su imagen se encuentra presente en varios productos culturales y ha servido para materializar los contenidos ideológicos, lo que puede ser constatado en varios sitios arqueológicos que corresponden a periodos diferentes. Este suceso en particular confirma de manera llana su importancia en el tiempo y espacio prehispánicos.

Así, por ejemplo, la cerámica puede dar cuenta fiel de esos contactos con las aves, puesto que la imagen de estas especies de psitácidos fue plasmada en vasijas mayas procedentes de diferentes sitios y periodos, como en las de Chamá, Las Flores y Nebaj en Guatemala; o como en las de Río Hondo en Belice, o bien en las de Oxkutzcab, Yucatán (Navarijo Ornelas, 1999), además de que figuran en las vasijas zoomorfas de Colima y en las de Monte Albán, Oaxaca. Por otro lado, la forma de los marcadores del juego de pelota en los sitios arqueológicos de Xochicalco, en Morelos, y de Copán, en Honduras, corresponden sin equívoco a cabezas de guacamaya.

Seler (2004: 127-128) observa que en los códices figuran loros y guacamayas dentro de las 13 aves que representaban las 13 estaciones del cielo y las 13 horas del día. Señala que los loros están colocados en la décimo tercera posición y la guacamaya en el décimo primer lugar, posiciones que según Seler hacen a ambos jugar un papel determinado como ave del sol y del fuego. Por su parte, Galindo Pérez (1997), en su estudio taxonómico sobre las especies que figuran en los Tonalamatl de Aubin, Borbónico y Borgia, reconoce y hace la identificación de la Guacamaya Roja (Ara macao) y del Cotorra o Loro Real (Amazona ochrocephala).

La importancia de estas especies en la cosmovisión fue tal que de hecho estuvieron ligadas a determinadas deidades, como se puede apreciar en el panteón mexica. Como muestra de ello Aguilera (1985: 55) comenta que Amazona era el ave que acompañaba a Citlalicue, "la de la falda de estrellas"; mientras que Xochipilli, "Príncipe flor", se encontraba engalanada con hermosas plumas de guacamaya.

No menos interesante es la información arqueológica que procede del sitio de Paquimé, Chihuahua, porque ahí se han podido recuperar cerca de 500 esqueletos de las dos especies de guacamayas, esto es, de la roja y de la verde (Ara macao y Ara militaris), cantidad por demás sugerente de su papel en la cultura.

La pintura mural es otra expresión significativa, puesto que las representaciones pictóricas que hoy se contemplan son el producto de un conjunto de ideas que maduraron y afloraron en su época. Dicho en otras palabras, lo que se observa en los muros es la consecuencia de un vínculo con la naturaleza y no una simple imagen dentro del repertorio iconográfico. Para poder representar en un muro a una especie de ave, o de cualquier otro ser vivo, mediaron las observaciones constantes que derivaron al paso del tiempo en un cúmulo de conocimientos cristalizadas en el establecimiento de una relación precisa entre lo que se ve, se recrea y las creencias e ideas de un pueblo, así como de una situación histórica particular. 
El inventario de imágenes de psitácidos en la pintura mural es considerable (Navarijo Ornelas, 1996; 2001 y 2008) (cuadro 1). Basta enumerar como ejemplo las especies reconocidas en el sitio de Teotihuacán, estado de México, pues en distintos muros se localizan magníficas representaciones: una Guacamaya Verde o Militar (Ara militaris) se halla en el corredor 15, mural 1 en Tetitla; o también se aprecia en los tres muros de un recinto porticado en el Pozo 10 en el sitio Purificación-Pirámides de Teotihuacán; o bien un Loro Frentiblanco (Amazona albifrons) se observa en el Templo de los Caracoles Emplumados situado abajo del Quetzalpapalotl. Todas estas representaciones transmiten información biológica y ecológica de primera mano, a la vez que proporcionan información sobre la cosmovisión (Navarijo Ornelas, 1996).

Cuadro 1. Especies de psitácidos representados en la pintura mural de siete sitios prehispánicos en México

\begin{tabular}{|c|c|c|}
\hline$T A X A$ & Nombre común & Sitio \\
\hline \multicolumn{3}{|l|}{$\begin{array}{l}\text { Orden/Familia/Especie } \\
\text { Psittaciformes } \\
\text { Psittacidae }\end{array}$} \\
\hline Aratinga canicularis & $\begin{array}{l}\text { Perico Frentinaranja, } \\
\text { Periquillo Común, Catarina, } \\
\text { Lorito }\end{array}$ & Jaltepetongo \\
\hline Ara militaris & $\begin{array}{l}\text { Guacamaya Verde, } \\
\text { Papagayo, Alo, Oop, } \\
\text { X-op }\end{array}$ & $\begin{array}{l}\text { Cacaxtla } \\
\text { Teotihuacán }\end{array}$ \\
\hline Ara macao & $\begin{array}{l}\text { Guacamaya Roja, } \\
\text { Papagayo, Alo, Mox, } \\
\text { Ah-k'ota, Oop, X-op }\end{array}$ & $\begin{array}{l}\text { Monte Albán } \\
\text { Xelhá }\end{array}$ \\
\hline Amazona albifrons & $\begin{array}{l}\text { Loro Frente Blanca } \\
\text { Loro Manglero, Cocha, } \\
\text { Cucha, Cabeza de Manta }\end{array}$ & $\begin{array}{l}\text { Calakmul } \\
\text { Jaltepetongo }\end{array}$ \\
\hline Amazona xantholora & $\begin{array}{l}\text { Loro Yucateco, Loro Ceja } \\
\text { Amarilla, Thuth, Toznene, } \\
\text { Xttut, E'xikin }\end{array}$ & $\begin{array}{l}\text { Teotihuacán } \\
\text { Xelhá }\end{array}$ \\
\hline Amazona sp. & Loro, Cotorra & Tamuín \\
\hline
\end{tabular}

Orden taxonómico según American Ornithologist's Union (2006).

Nombres comunes tomados de Birkenstein (1981).

Sin ahondar en el tema las evidencias expuestas aquí ponen de manifiesto la importancia cultural que, tanto loros como guacamayas, tuvieron en la vida 
cotidiana y ritual de los pueblos prehispánicos, pues su integración en diferentes contextos comprendió varios puntos de la geografía mesoamericana, incluyendo algunos sitios que corresponden al área de oasisamérica. De hecho, se puede afirmar que esa importancia permanece vigente en diversas expresiones populares actuales, como danzas y textiles.

\section{Propósito}

A lo largo y ancho del territorio nacional se hallan repartidos numerosos sitios arqueológicos, y en varios de ellos se encuentran excepcionales muestras pictóricas con valiosa información que hace referencia al medio natural y a diversos aspectos de la cultura productora de la obra. De modo específico se ha trabajado en la documentación de un inventario importante de especies de aves como parte del discurso pictórico (Navarijo, 1996, 2001, 2008), lo que permite estudiar las imágenes avifaunísticas, entre otras cosas, con información biológica, además de la arqueológica inherente, teniendo como fin contribuir con referencias biológicas para enriquecer las interpretaciones de las escenas.

Por tanto, si se considera que el entorno natural y la cultura forman un binomio que es parte del pensamiento mesoamericano, y tomando como base la identidad taxonómica de los individuos de aves recreados en dos sitios en particular — uno situado en la zona maya y el otro ubicado en el Altiplano—, se puede trabajar con argumentos que ayuden a explicar y validar, bajo la perspectiva de la ornitología, la presencia física de los psitácidos en la pintura mural. Entonces la hipótesis sería que dicha presencia obedeció a una necesidad ideológica específica en un momento histórico particular, pues en ambos casos las imágenes mismas y el contexto brindan suficientes evidencias que apuntan hacia la existencia de una relación simbólica con los conceptos de vida, fertilidad, movimiento y temporalidad.

\section{Descripción de las aves en las escenas pictóricas}

Para el establecimiento de la identidad de los individuos de aves se tomaron en cuenta las características físicas conspicuas y distintivas de las especies, así como las actitudes conductuales manifiestas. A ello se sumó la posición de las imágenes en la escena, estudiada de acuerdo con los niveles de representación gráfica, así como los niveles de integración temática de los elementos iconográficos en el discurso pictórico (Navarijo Ornelas, 2000). Aún cuando la representación de una especie de ave sea tomada como naturalista o revestida con atributos simbólicos, existe un equilibrio entre la naturalidad de las formas y las fórmulas metafóricas: la fisonomía o las actitudes que denuncian un patrón conductual fueron 
exaltadas sobre otros caracteres. Esto involucra un juego de valoración hacia una especie de ave en exclusiva para ser utilizada como instrumento metafórico (Navarijo Ornelas, 2000: 7).

\section{Caso 1}

En la estructura 86 o La Casa de los Pájaros, que pertenece al grupo B en el sitio de Xelhá, ubicado al sur de la ciudad de Playa del Carmen en Quintana Roo, se conserva el mural 1 conocido como Los pájaros, bautizado así porque la composición consta de un conjunto de, por lo menos, 18 individuos de aves de acuerdo con los trazos que aún se conservan. Estas representaciones son el elemento iconográfico substancial y ocupan diferentes posiciones, de manera tal que se distribuyen en dos escenas enmarcadas y separadas en la porción central por un cartucho. El análisis de los diseños revela que fueron personificadas dos especies de la familia Psittacidae (Navarijo Ornelas, 2001).

Para los fines de este estudio sólo se examinó la escena que corresponde al lado derecho según la vista del espectador, por ser la mejor conservada (figura 1). En ella se distinguen en las posiciones 1 y 9 las siluetas de un loro o Amazona, según el aspecto de los cuerpos compactos y rechonchos con tonalidades azul/ verde y por la cola corta y cuadrada, a diferencia de lo que se observa en las

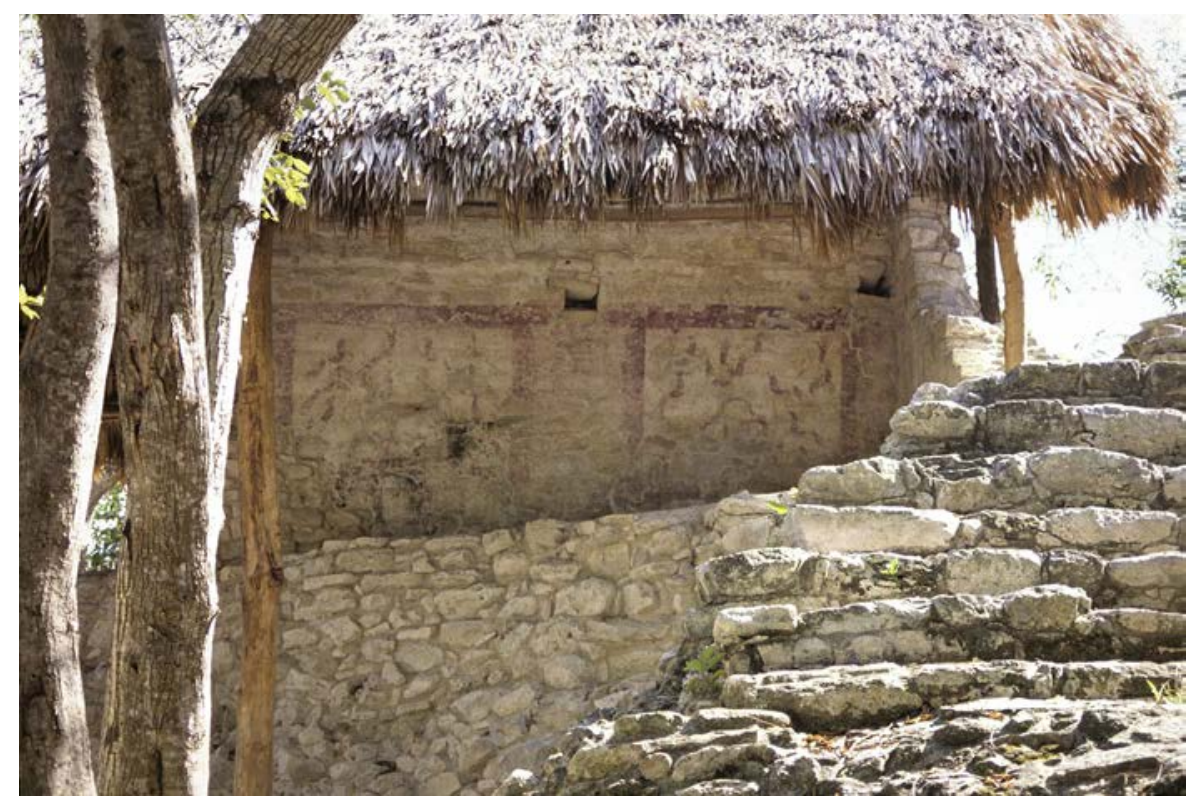

Figura 1. Vista del mural 1 conocido como Los pájaros, estructura 86 o La Casa de los Pájaros que pertenece al grupo B en el sitio de Xelhá, ubicado al sur de la ciudad de Playa del Carmen en Quintana Roo (fotografía de Leticia Staines Cicero, 1994) 
otras siete aves de la escena (figura 2). Como característica distintiva se advierte la cabeza voluminosa y el cuello corto, además de un parche ocular rojizo y un pico fuerte, ganchudo y corto.

A juzgar por estos rasgos físicos y revisando la distribución geográfica de las especies se pueden plantear dos opciones: el Loro Yucateco (Amazona xantholora (Gray) 1859), o bien el Loro Frentiblanco (Amazona albifrons (Sparrmann) 1788). Ambas especies de loros son residentes comunes en la península de Yucatán, aunque $A$. xantholora es más abundante en las selvas deciduas y $A$. albifrons lo es en las lluviosas. Estos loros son muy parecidos, con una talla promedio de entre 225 a 250 mm (Peterson y Chalif, 1989: 146-147; Forshaw, 1977: 519).

Los diseños del resto de las aves corresponden a representaciones acertadas de la Guacamaya Roja o Escarlata (Ara macao (Linnaeus)), ya que los cuerpos se pintaron grandes y compactos en comparación con el de los loros. De hecho son aves que llegan a medir entre 850 y $950 \mathrm{~mm}$ y poseen una cola larga, la cual se dibujó abierta mostrando las plumas dispuestas en abanico. También es indicativa de esta determinación la coloración rojiza del cuerpo y de la cola, así como el área desnuda apropiadamente insinuada, porque ésta es de un tono rosa pálido en los individuos en su estado natural. Las plumas cobertoras de las alas son amarillas y las grandes plumas de vuelo son de color azul (Álvarez del Toro, 1980: 81; Forshaw, 1977: 362; Peterson y Chalif, 1989: 144). La cola larga de la Guacamaya Roja la distingue de entre los otros miembros de la familia, sobre todo cuando se les observa en vuelo (figura 3).

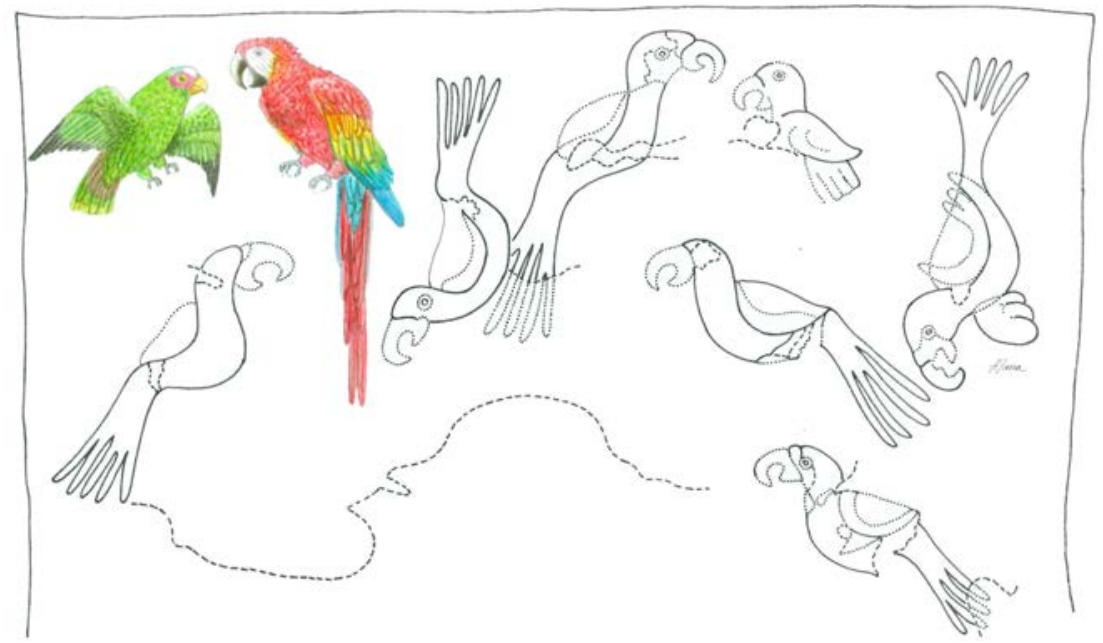

Figura 2. Esquema de la escena izquierda del mural 1 conocido como Los pájaros, de la estructura 86 o La Casa de los Pájaros que pertenece al grupo B en el sitio de Xelhá, en Quintana Roo, en donde se aprecia la imagen de nueve aves en movimiento (dibujo de Albino Luna Sánchez, enero del 2011) 


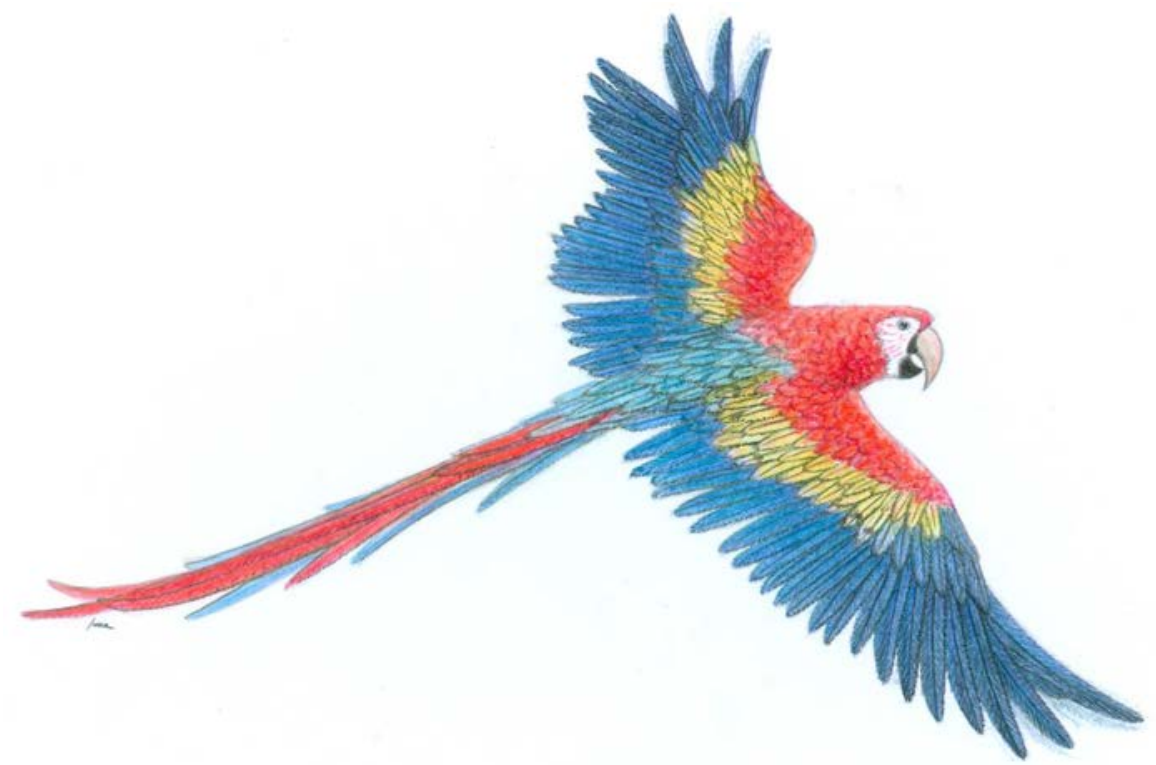

Figura 3. La larga cola flameante de la Guacamaya Roja la distingue de entre los otros miembros de la familia, sobre todo cuando se le observa en vuelo (dibujo de Albino Luna Sánchez, agosto del 2011)

Los registros de la distribución original de la Guacamaya Roja revelan que se extendía desde el noreste de México hasta Bolivia y Brasil en Sudamérica; y en nuestro país fue registrada la especie en los estados de Tamaulipas, Veracruz, Tabasco, Campeche, Oaxaca y Chiapas (Friedmann, Griscom y Moore, 1950: 125; Howell y Webb, 1995: 337); además existen pruebas de que Ara macao fue introducida a la isla de Cozumel como un artículo de comercio (Navarijo Ornelas, 2001). Sin embargo, en la actualidad las poblaciones de Ara macao se han reducido por la pérdida de sus hábitats y la especie está considerada por la NOM-059 como en peligro de extinción (Semarnat, 2010).

\section{Caso 2}

En la pintura mural del sitio de Cacaxtla en Tlaxcala se reconocen dos imágenes de cuerpo completo de una Guacamaya Verde o Militar (Ara militaris (Linnaeus) 1766). Una de ellas se encuentra en el muro oriente del Templo Rojo y otra más se sitúa en el muro sur del Pórtico del Edificio A. Tras examinar las características físicas y el color, así como las actitudes de vuelo y percheo manifiestas respectivamente, se puede afirmar que se trata de recreaciones sencillas acordes con los patrones conductuales y sin estilizaciones. 
A diferencia del caso de Xelhá, en Cacaxtla las guacamayas no constituyen el elemento iconográfico cardinal de las composiciones, puesto que las escenas lucen numerosos componentes. Sin embargo, al haber sido trazadas con el cuerpo completo y al tener una proporción apropiada con respecto a los demás elementos, adquiere una importancia específica pues su presencia y posición adjetivan y complementan el mensaje pictórico. Su nivel de integración temática es secundario, aunque preciso.

Por otra parte, en la escena del muro oriente del Templo Rojo destaca la imagen de un hombre viejo que lleva un bastón y cuyo atuendo está hecho a base de piel de jaguar. Frente a él se muestran dos plantas de color azul: se trata del maíz y del árbol tropical de cacao con sus flores y frutos. Entre estos dos elementos de origen vegetal se ubica una guacamaya de perfil con actitud de posarse sobre el cacao, el que parece surgir de una serpiente azul (figura 4).

La escena sintetiza aspectos de una de las actividades de gran importancia en la época, el comercio, pues se destaca la presencia de ciertos productos. Desde mi punto de vista es a través de ellos que quedó expresada una valoración hacia la variedad de los recursos naturales locales y foráneos: maíz, cacao, maguey, plumas preciosas y los diferentes animales recreados en la cenefa acuática que la enmarca, siendo el agua el elemento primordial del cual depende la subsistencia.

La segunda imagen de guacamaya en Cacaxtla se ubica en el muro sur del Pórtico del Edificio A, donde se muestra a un personaje revestido con elementos de ave y parado sobre una serpiente. A la izquierda del personaje, a nivel de su cadera, se dibujó un ave con tonos azules cuyas alas están extendidas y se encuentra mirando hacia el hombre-ave-serpiente (figura 5). La cabeza se pintó de perfil y de este modo se aprecia un copetillo no muy corto, así como un pico fuerte entreabierto y que por su forma es el característico de la especie, pues está adaptado para romper cáscaras duras con facilidad. Esta escena también se haya delimitada por una banda azul con animales de diferentes especies, como tortugas, serpientes y caracoles que pertenecen a hábitats diferentes (Polaco, 1986).

La Guacamaya Verde o Militar (Ara militaris) es una ave robusta que alcanza una talla de 685 a 760 milímetros y un peso aproximado de 900 gramos. El plumaje del cuerpo es de tonalidad verde olivo, mientras que la frente y el área entre el ojo y el pico es color rojo; pero la parte desnuda del rostro presenta una coloración rosada pálido con hileritas de finas plumas negro verdosas (figura 6). Por encima del ojo se observan líneas de plumitas rojizas, mismas que podrían ser consideradas en términos iconográficos como un tipo de ceja. Las plumas para el vuelo y las de la espalda baja son de color azul y el envés de las alas es amarillo, situación que particularmente se observa en el individuo del mural sur del Pórtico del Edificio A. El color de la cola larga y puntiaguda es granate pero se torna azul en las puntas (Álvarez del Toro, 1980: 80-81; Peterson y Chalif, 1998: 143). 


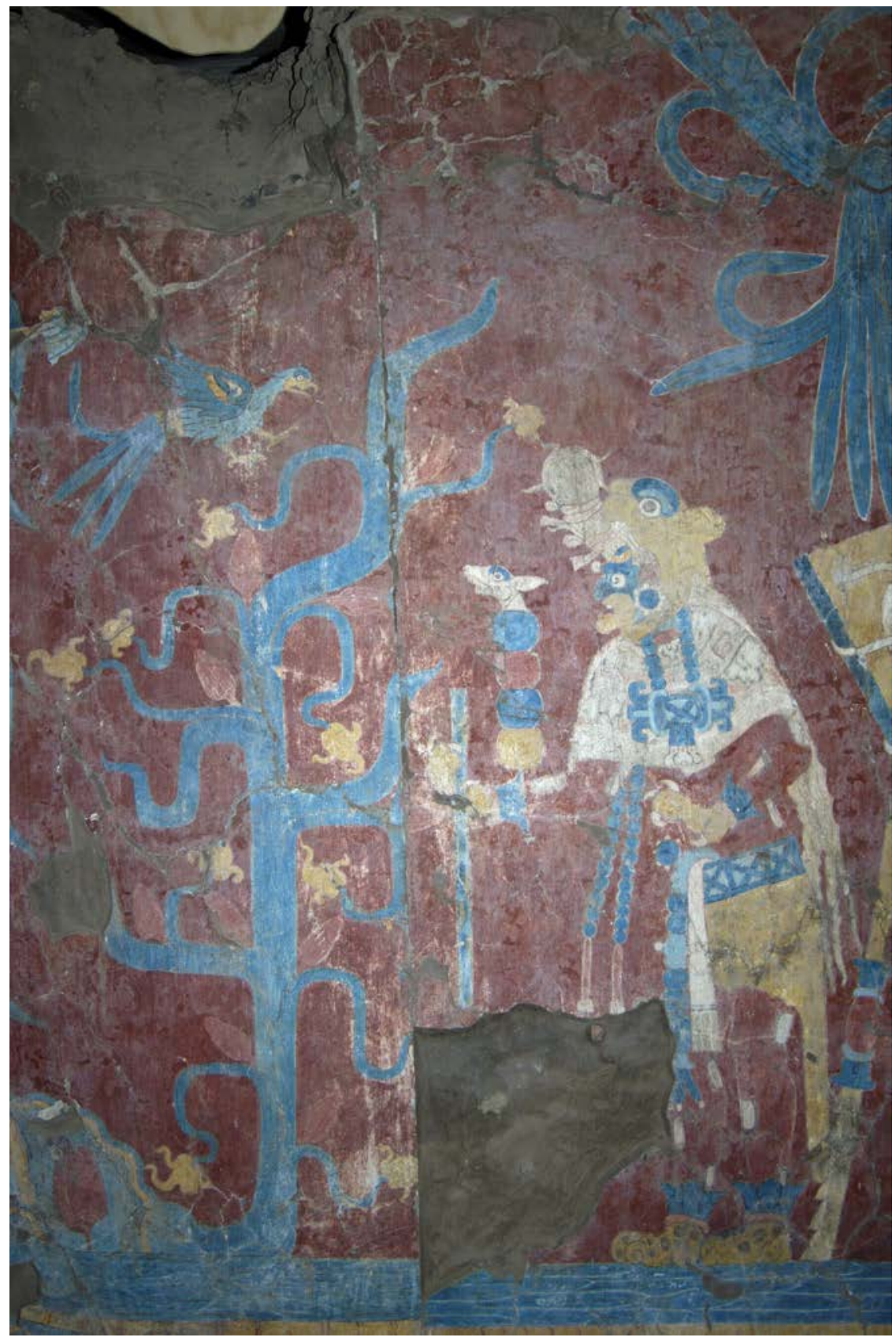

Figura 4. Situada entre una planta de maíz y un árbol de cacao figura de perfil una Guacamaya Verde o Militar (Ara militaris) con actitud de posarse sobre el cacao (fotografía de Ricardo Alvarado Tapia, 2008) 


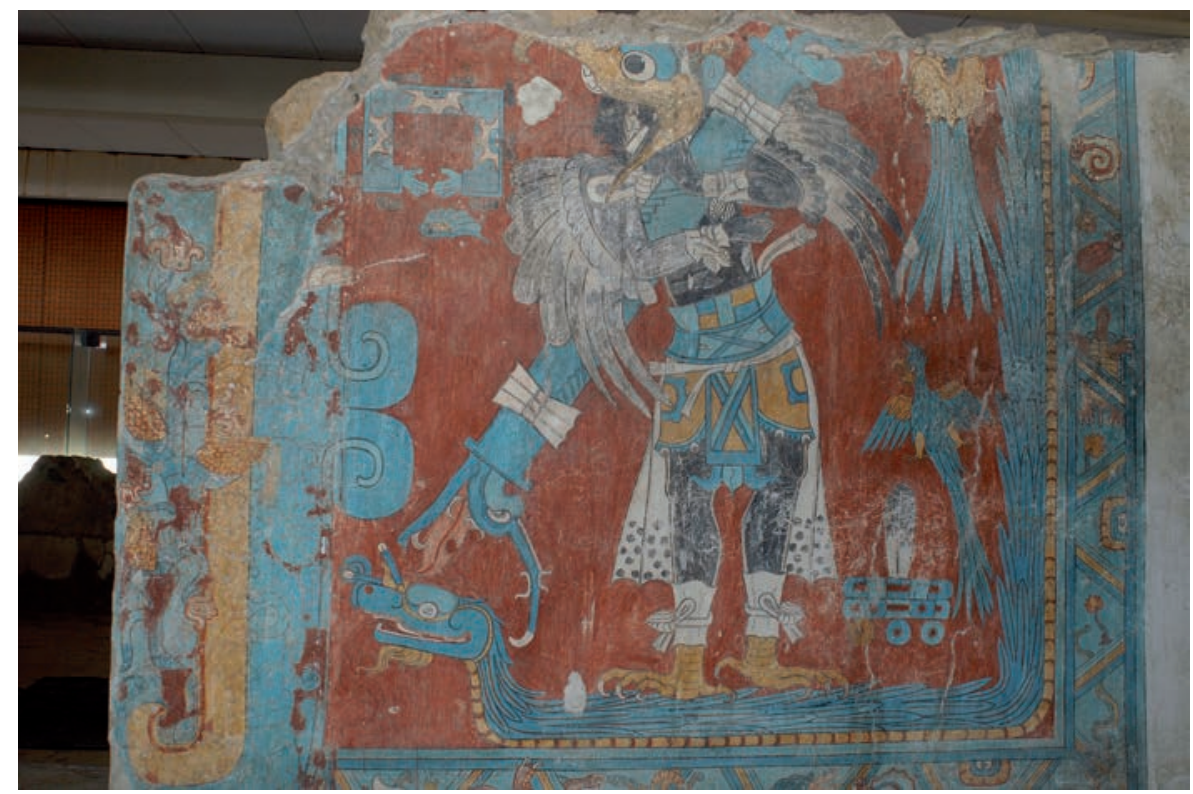

Figura 5. La segunda imagen de Guacamaya en Cacaxtla se ubica en el muro sur del Pórtico del Edificio A, donde se muestra a un personaje revestido con elementos de ave parado sobre una serpiente (fotografía de Ricardo Alvarado Tapia, 2008)

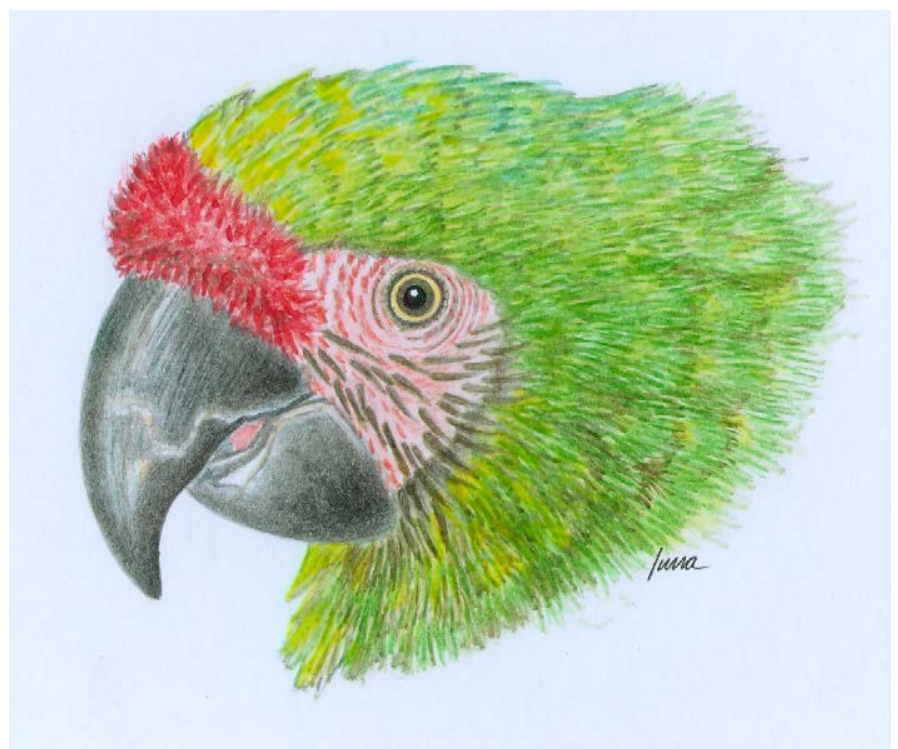

FigurA 6. Las características faciales y conductuales que distinguen a la Guacamaya posibilitan un cotejo simbólico con Tláloc (dibujo de Albino Luna Sánchez, enero del 2011) 
La Guacamaya Verde se distribuye de forma discontinua desde México hasta el norte de Argentina, puesto que habita en selvas tropicales caducifolias y subcaducifolias y de manera temporal en bosques de pinos y encinos e, inclusive, en zonas áridas en un rango de altitud que va desde el nivel del mar hasta los $2500 \mathrm{msnm}$. En México se tienen registros de poblaciones aisladas en la vertiente del Pacífico desde el sureste de Sonora y suroeste de Chihuahua hasta Oaxaca y Chiapas. En el Golfo de México se le encuentra en Tamaulipas, y en el centro de la República desde los estados de Zacatecas, sur de Nuevo León, San Luís Potosí, hasta México, Querétaro y Michoacán (Peterson y Chalif, 1989: 143144). Sin embargo, debido a la fragmentación de sus poblaciones la especie está catalogada como vulnerable y la Norma Oficial Mexicana la considera en peligro de extinción (Semarnat, 2010).

\section{Propuesta de participación en el discurso pictórico}

A partir de la determinación de la identidad taxonómica de las aves que se muestran en las escenas estudiadas, y tras la revisión de las generalidades de sus hábitos y hábitat, se concluye que las aves representadas son miembros de la familia Psittacidae. Se trata de un loro (el Yucateco, Amazona xantholora, o bien el Frentiblanco, Amazona albifrons) y de las guacamayas Roja y Verde (Ara macao y A. militaris); así, el razonamiento de participación en el discurso pictórico de Xelhá y de Cacaxtla se efectúa desde la perspectiva ornitológica.

Con el propósito de aportar elementos para la comprensión de la presencia de estas aves en las tres escenas señaladas, es menester tomar en cuenta que tanto loros como guacamayas acostumbran andar en parejas o en grupos pequeños. Estas parvadas se conducen como una unidad funcional y presentan dos picos de actividad visiblemente diferenciados, esto es: uno ocurre por la mañana y el otro al atardecer, lo que en términos del reloj biológico marca dos sucesos definidos que sientan un pasado, un presente y un futuro. El primero de ellos se inicia justo antes de la salida del Sol, cuando el grupo emprende su vuelo desde sus territorios de reposo hacia los terrenos de alimentación. El segundo se produce cuando al atardecer las aves regresan al lugar de descanso nocturno.

Es representativo lo observado en Amazona albifrons. Durante los periodos de alta actividad el estado de excitación de la parvada es muy evidente a través de bostezos, del acicalamiento, de la limpieza del pico o bien de su movimiento constante y de sus juegos sociales, como unir sus picos o las patas y las frecuentes vocalizaciones y actitudes para llamar la atención. Esta conducta de excitación social parece funcionar para cohesionar al grupo durante la actividad diaria.

Registrar en la memoria individual o colectiva los movimientos cíclicos de las aves, como loros y guacamayas, poseé suma importancia porque la observación y concepción de estos eventos involucra la toma de conciencia de que la actividad 
de cualquier ser viviente es un fenómeno que siempre se manifiesta con una variación regular y no como un proceso continuo, es decir, es aprender a ver la vida como un fenómeno rítmico. Por tanto, los periodos de luz y oscuridad debidos a la eterna rotación de la Tierra en su curso alrededor del Sol concretan estímulos elementales, para regir las acciones de todos los seres vivos.

El escrutinio de la naturaleza, de los fenómenos que ocurren en el medio ambiente, es siempre un quehacer sistemático y repetido. Este proceder hace posible efectuar predicciones y orientar el comportamiento social de acuerdo con esos conocimientos (Broda, 1997: 52). Al respecto, Niederberger (1996: 29) señala que el calendario agrícola, la vida ritual e incluso la literatura poética prehispánica estuvieron profundamente marcados por el ciclo anual de lluvias.

Interpretar los signos atmosféricos como la nubosidad, los vientos, etcétera, así como los que brindan las plantas, por ejemplo, la foliación de los árboles en cierta época del año, conforma un cuerpo de conocimientos intuitivos que se hicieron necesarios para el desarrollo de la vida cotidiana y ritual. De igual manera, advertir los desplazamientos habituales e invariables gracias al tamaño, al color y a los ruidos propios de las guacamayas y loros, es observar una señal basada en la conducta. Con certeza aquella fue tomada como un informe práctico y directo acerca de la temporalidad, en el sentido de duración o de separación de sucesos sujetos a cambio. Cabe recordar que diferentes especies animales estuvieron integradas a la vida cotidiana de todos los pueblos mesoamericanos, lo que en buena medida facilitaba a los hombres "leer" en los hábitos de los animales signos sobre los fenómenos climáticos; con ello podrían hacer predicciones sobre el tiempo, realizar augurios de vida, enfermedad y muerte, así como lograr establecer los momentos adecuados para las ceremonias y el juego.

En el pensamiento prehispánico la Guacamaya Roja ocupó un lugar de importancia. Sobre ello, León-Portilla (1986: 39) consigna que las fuentes documentales del siglo xvi relatan que la guacamaya estuvo asociada con ciertos conceptos y con deidades, como sucede con el concepto de Kinh o Kin* (Sol-Día-Tiempo), el cual posee diversas connotaciones y evocaciones con variantes zoomorfas. Entre los mayas de Yucatán, kinh se presenta ligado con varios títulos de la que parece ser una misma deidad. Una de ellas es Kinich Kak Moo, "El señor de rostro solar, guacamaya de fuego", al que con frecuencia se le identifica con la deidad solar Itzamná.

Tocante a esta deidad, Garza (1995: 50) explica que era un dios con rayos de fuego, el cual encarnado en una Guacamaya Roja bajaba en Izamal a quemar las ofrendas de los hombres en un templo dedicado a él; y agrega que se recurría a esta deidad cuando había desgracias para saber el remedio y ver el futuro. La justificación ofrecida por Garza (1995) es que el fuego solar, como una de las grandes fuerzas naturales, posee un significado ambivalente. El fuego solar es la energía que permite la vida en la tierra, pero es también aquella capaz de ocasio-

\footnotetext{
* Nota del editor. Se respetó la ortografía propuesta por la autora.
} 
nar la muerte si es descargada en exceso. Estos efectos se podían experimentar durante las sequías.

Precisamente sobre estas largas plumas rojas con la mancha azul en el extremo, Seler (2004: 128) apunta que eran llamadas por los antiguos mexicanos cueçalin, "flama". Este informe no sólo llama la atención debido a la calidad específica de las observaciones; también es sugerente por la asociación que propone el calificativo acuñado con los conceptos de calor, fuego, resplandor; por tanto, el propio Sol queda comprendido. Así, todo esto descubre la trama de las posibles asociaciones que se gestaban entre las características físicas de un ave y otros elementos del entorno.

También figura una guacamaya en los contextos cosmológicos, pues estos aseguran el descenso de esta ave a la Tierra y su papel de vigilante de la piedra (la Tierra) allá en el Acantún. Dicha ave representa a Kinich Kak Moo, Guacamayade-Ardiente-Rostro-Solar, el Sol del cenit en la cosmovisión maya, según apunta Montoliu Villar (1991: 155).

Esta clase de referencias sumadas a las características físicas y los hábitos de la Guacamaya Roja o Escarlata permiten formular las siguientes asociaciones simbólicas. En primer lugar es viable que se llegara a establecer un fuerte vínculo entre el color rojo escarlata del plumaje y el hecho de que en la distribución cuatripartita del mundo, el rojo fuera asignado al punto cardinal del este, por donde nace o se asoma el Sol, lo cual justifica el nombre de Guacamaya-de-ArdienteRostro-Solar en el terreno comparativo.

En segundo lugar, priva la eventualidad de que los picos de actividad diferenciados de loros y guacamayas pueden ser vistos como modelos de temporalidad. Esta última en los libros del Chilam Balam (en los textos de contenido cronológico como la "primera rueda profética de un doblez de katunes") se interpreta a través de la deidad solar Rostro del Sol, Guacamaya de Fuego, Kinich Kak Moo, quien preside y gobierna el periodo de un katún 6-Ahau (León-Portilla, 1986). Se presume que en las concepciones de Kinh, todos los momentos del tiempo son llegadas y presencias de rostros de dioses que se aúnan y apartan sucesivamente dejando sentir sus influencias (León-Portilla, 1986), esto es, existe una secuencia de eventos que se pueden equiparar con la actividad rutinaria de la guacamaya, siendo esta una hierofanía.

Asimismo, es factible incorporar a estas concepciones la ya legendaria perspectiva antropocéntrica sobre el interés que ha tenido en los hombres de todos los tiempos la capacidad de vuelo de las aves. De hecho, el vuelo y los marcados desplazamientos de las guacamayas se pueden conjugar con la circunstancia de que se trata de aves muy ruidosas y gregarias que, al perchar de manera conjunta, dan la impresión de una mancha escarlata en movimiento enérgico e inagotable. Por tanto, lo plasmado en el mural Los pájaros pudo inspirar, desde mi punto de vista, un elemental ejercicio de raciocinio coherente sobre el concepto de tiempo a partir de la realidad conductual observada en las guacamayas y loros y de su asociación conceptual con el Sol-día-tiempo. 
El dinamismo de estas aves permite suponer que los mayas establecieron un modelo para materializar la idea de una naturaleza dinámica donde existen espacios y tiempos precisos. ¿Acaso no fue el estado del tiempo una de las mayores preocupaciones de los mayas y, en general, de todos los pueblos mesoamericanos? Sin vacilación, la prevención de las condiciones climáticas ha sido crucial para los pueblos cuyos cultivos dependen del temporal. De ahí el origen de los ritos propiciatorios, a los cuales se agregan la llegada de algunas aves como pronósticos de lluvia en diferentes lugares de la geografía mexicana o bien el canto de las ranas o el vuelo hacia abajo de las luciérnagas, según lo recogido por Katz (1994: 111) entre los mixtecos actuales.

Por lo que respecta al análisis de la representación de la Guacamaya Verde o Militar, es de utilidad llamar la atención sobre las tonalidades verdes y azules en el plumaje. El color posee su propio valor de expresión al ejercer una poderosa influencia en la mente o percepción de una persona; provoca, de este modo, reacciones y emociones pues el azul es el color vinculado al cielo, al agua y al día, entre otras nociones de importancia, además de guardar una fuerte relación con el Sol (de hecho, la guacamaya estuvo vinculada al astro rey). En este sentido es conveniente recordar que en el mundo mesoamericano los objetos de jade, las plumas azules, de preferencia las de quetzal o las de la guacamaya, así como la producción del azul maya tuvieron, en el ámbito conceptual, cualidades mágico-religiosas asociadas a los rituales de la fertilidad que, a su vez, se pueden traducir en poder.

Como ya se mencionó, la productividad de los campos y en consecuencia la obtención de alimentos siempre ha sido una de las grandes preocupaciones del ser humano, ya que necesita garantizar la existencia familiar y dar curso a todas las actividades económicas y sociales. Esta realidad hace que sea un asunto vital para un campesino asegurar su alimento con el beneficio de los frutos de la tierra, como el maíz, el frijol, la calabaza, el chile, etc.; pero, para la clase gobernante, representa un objetivo capital por ser la pauta para generar un dominio significativo sobre la población.

El maíz fue y sigue siendo capital, y ello se debe a que todas las partes de la planta tienen un uso específico: esta versatilidad justifica su valor. Amén de la variedad de usos materiales, el maíz también alcanzó un papel trascendente en la cosmovisión mesoamericana por ser la materia y la imagen de la sobrevivencia, de tal suerte que los primeros hombres se hicieron de esta planta, lo que motivó que se le llegara a considerar como un regalo divino. Al mismo tiempo, se le imaginó como el eje sobre el que se ordenaba el mundo y varias deidades estuvieron relacionadas con él. De esta manera, la planta de maíz implica signos de continuidad cultural al llevarse a cabo ritos y ceremonias en torno a las etapas de cultivo y consumo. Según Niederberger (1996: 11-15), esta importancia continúa hasta el siglo xvi, ya que el maíz junto con otras plantas nativas sostenía a una considerable parte de la población de la época estimada en más de 40 millones de habitantes en el Altiplano Central de México. 
En el mensaje pictórico de los murales del Templo Rojo se descubren implícitos los conceptos de fertilidad, de regeneración, puesto que las prácticas agrícolas involucran las tareas de siembra, cultivo, riego, crecimiento, floración, fructificación y cosecha. En el transcurso de todo este proceso se halla tácito un ciclo de vida y muerte, en donde media la regeneración y en donde el agua, como elemento primordial, fue divinizada en todas sus variantes. El sobrevalorar el agua tiene sentido, pues de ella dependen los cultivos de temporal, lo que a su vez comprende necesariamente contar con conocimientos puntuales sobre los ciclos hidrológicos. Tal vez asumiendo esta lógica se asoció a la lluvia fertilizadora de la tierra con Tláloc y, al agua que inunda y fertiliza con Ayauh Cozamalotl.

Por ende, el maíz como sustento principal y el agua como el elemento primordial son la imagen de un ciclo agrícola supeditado a un ciclo hidrológico. Estos dos elementos iconográficos fueron pintados de color azul. A esta realidad bien se puede agregar como complemento interpretativo la existencia de una actividad cíclica por parte de las guacamayas para alimentarse y para llevar a cabo la reproducción, lo que equivale a lograr el sustento y la preciada regeneración; además se debe sumar ese vistoso plumaje con tonos azul y verde. Todo esto, en síntesis, nos permitiría establecer una asociación colorida y ruidosa como señal inequívoca de sucesos ligados a la temporalidad que influye en la prosperidad de las cosechas. De no ser así, ¿por qué se le utilizó como un elemento iconográfico asociado a plantas preciosas como el maíz y el cacao?

Concerniente a la presencia de un árbol de cacao (Theobroma cacao) junto a una planta de maíz en un mural que se localiza en el Altiplano, es de interés llamar la atención sobre el hecho de que se trata de un árbol tropical que requiere de clima húmedo y de suelo rico y poroso para poder crecer. Aún cuando sus frutos maduran durante todo el año, de manera habitual se realizan dos cosechas; la principal se inicia hacia el final de la estación lluviosa y se continúa hasta la llegada de la estación seca (esto revela sencillamente dos periodos en el transcurso del año). En conclusión, el cacao en Cacaxtla es mostrado como un recurso, un producto objeto de comercio, así como una imagen de la manutención, de la vida y, simultáneamente, como uno más de los regalos divinos, pues el cacao llegó a simbolizar, al menos para los mayas, el vigor físico y la longevidad, aparte de haber sido usado en los rituales religiosos.

A la par, como punto de apoyo en la comprensión y justificación de la presencia de una guacamaya en el Templo Rojo, se puede plantear una posible asociación de esta ave con Tláloc: entre los rasgos esenciales que facilitan reconocer a esta deidad están los dos característicos anillos oculares o anteojeras grandes, la boca abierta y el color azul. Estos rasgos constantes en las representaciones de las deidades de la lluvia admiten un cotejo simbólico con las áreas faciales (desnudas y blanquecinas con tonos rosados y cruzadas por pequeñas líneas de plumitas negro-verdosas) que ostentan las guacamayas. Además, la presencia de un pico robusto (figura 6) igualmente puede ser comparada con la tosca forma de la nariz y boca del Cocijo zapoteco, ya que tiene el aspecto de una máscara 
bucal; o bien, con la nariz pronunciada con la que es identificado el Chaac maya. A estos caracteres físicos se suman los ya mencionados patrones de actividad diaria para alimentarse y los estacionales de reproducción de las guacamayas.

El núcleo de estos dos materiales de discusión sirve de informe práctico, directo y certero acerca de la temporalidad. Ambos pueden ser igualados con los ciclos hidrológicos vitales para lograr un resultado provechoso en la cosecha de temporal, puesto que las atribuciones de Tláloc son, de acuerdo con la información recogida por Sahagún (1969: 45) en su capítulo IV: "tenían que él daba las lluvias para que regasen la tierra, mediante la cual lluvia se criaban las yerbas, árboles y frutas y mantenimientos: también tenían que él enviaba el granizo y los relámpagos y rayos, y las tempestades del agua, y los peligros de los ríos y de la mar". Esto denota que la deidad estaba asociada con todos los fenómenos meteorológicos conectados con la lluvia y con las corrientes de agua.

No hay que olvidar que la importancia otorgada por los mesoamericanos al agua radica en ser la fuente de la vida y la base para el sustento sostenido en el maíz, el frijol, la calabaza, el tomate, el chile y los recursos acuáticos. Es decir, se le consideró el elemento primordial, en particular durante una de las cuatro edades cósmicas anteriores a la que se vivía (León-Portilla, 1992: 7-14).

Entonces, bajo esta tesis, el elemento iconográfico "guacamaya" en el mural oriente del Templo Rojo bien pudo tener la función de representar, conmemorar y reafirmar la importancia de los conocimientos sobre los ciclos de la vida, la fertilidad y, por tanto, también sobre el papel del maíz y del cacao en la cotidianidad y en la vida ritual. El agua representaba fertilidad y vida confirmadas por el color azul.

\section{Conclusiones}

Por diferentes caminos los seres humanos han buscado entender el mundo que los rodea con sus constantes y variaciones. Como parte de esa eterna búsqueda las aves han adquirido un papel protagónico. Es así que la presencia de estos animales como elementos iconográficos en la pintura mural de varios sitios arqueológicos en México, aunque sean de distintas especies, poseee una gran importancia cultural al estar inscritas en el lenguaje pictórico como un vehículo que da cuenta de diferentes sucesos impregnados de la ideología de los pueblos que las crearon.

De acuerdo con los casos que han sido presentados en este espacio es permisible dejar asentado que, para fungir como objeto simbólico, medió la observación y valoración de las cualidades físicas y conductuales de las aves. Nuestros argumentos proponen que tanto loros como guacamayas podrían estar actuando a manera de instrumento metafórico de un evento de naturaleza temporal debido a su fisonomía y su actividad cotidiana. Así se dio lugar a la integración de los sistemas de creencias encaminados al raciocinio de los fenómenos naturales a fin de predecirlos y contar con herramientas para controlarlos. 
Ante este panorama es razonable pensar que en un principio pudo surgir en forma espontánea el aprecio por los recursos naturales. Posteriormente o bien en forma unísona también se fueron forjando los procesos jerárquicos y de simbolización de ciertas especies animales para que éstas fueran vinculadas a un cuerpo de creencias que contribuirían a conformar una explicación coherente sobre los heterogéneos acontecimientos de la vida.

Dadas estas circunstancias no es de extrañar que la periodicidad circadiana y estacional de loros y guacamayas haya sido considerada como un parámetro de referencia para el desarrollo de ciertas actividades, principalmente aquellas relacionadas con la producción de alimentos.

\section{BIBLIOGRAFÍA}

Aguilera, Carmen

1985 Flora y fauna mexicana. Mitología y tradiciones. México: Everest (Colección Raíces Mexicanas).

Álvarez del Toro, Miguel

1980 Las aves de Chiapas. 2a edición. Tuxtla Gutiérrez: Universidad Autónoma de Chiapas.

American Ornithologist's Union

2006 Check-list of North American Birds. Washington, D.C.: 7th American Ornithologist's Union.

Birkenstein, Lillian

1981 Native names of Mexican birds. Washington, D.C.: Department of the Interior, Fish and Wildlife Service (Resource Publication, 139).

Broda, Johanna

1991 "Cosmovisión y observación de la naturaleza: el ejemplo del culto de los cerros en Mesoamérica”, Arqueoastronomía y etnoastronomía en Mesoamérica. Johanna Broda, Stanislaw Iwaniszewski y Lucrecia Maupomé (eds.). México: Universidad Nacional Autónoma de México, Instituto de Investigaciones Históricas (Serie de Historia de la Ciencia y la Tecnología), 461-500.

1997 "El culto mexica de los cerros de la Cuenca de México. Apuntes para la discusión sobre graniceros", Graniceros, cosmovisión y meteorología indígenas de Mesoamerica. Beatriz Albores y Johanna Broda (coords). México: El Colegio Mexiquense / Universidad Nacional Autónoma de México, 49-90.

Forshaw, Joseph M.

1977 Parrots of the World. Nueva Jersey: T.F.H. Publications. 
Friedmann Herbert, Ludlow Griscom y Robert T. Moore

1950 Distributional Check-List of the Birds of Mexico. Part I. Berkeley: The Club (Pacific Coast Avifauna, 29).

Galindo Pérez, Hugo

1997 "Identificación taxonómica de las especies de aves que aparecen en los Tonalamatl de Aubin, Borbónico y Borgia”, tesis de licenciatura en Biología. México: Universidad Nacional Autónoma de México / Escuela Nacional de Estudios Profesionales Iztacala.

Garza, Mercedes de la

1995 Aves sagradas de los Mayas. México: Universidad Nacional Autónoma de México, Facultad de Filosofía y Letras, Centro de Estudios Mayas.

Herskovits, Melville J.

1995 El hombre y sus obras. La ciencia de la antropología cultural. México: Fondo de Cultura Económica.

Howell, Steve N. y Sophie Webb

1995 A guide to the birds of Mexico and Northern Central America. Nueva York: Oxford University Press.

Katz, Esther

1994 "Meteorología popular mixteca: Tradiciones indígenas y europeas", Time and the meeting of two worlds. Stanislaw Iwaniszewski, Arnold Lebeuf, Andrzej Wiercinski y Mariusz S. Ziólkwski (eds.). Varsovia: Warsaw University, Center for Latin American Studies (Studies and Materials, 10), 105-122.

León-Portilla, Miguel

1986 Tiempo y realidad en el pensamiento maya. México: Universidad Nacional Autónoma de México, Instituto de Investigaciones Históricas (Serie de Culturas Mesoamericanas, 2).

1992 "El agua: universo de significaciones y realidades", Mesoamérica. Ciencias, 28: 7-14. México: Universidad Nacional Autónoma de México.

Montoliu Villar, María

1991 "Conceptos cosmológicos de los antiguos mayas de Yucatán estudiados en el Chilam Balam de Chumayel", Arqueoastronomía y etnoastronomía en Mesoamérica. Johanna Broda, Stanislaw Iwaniszewski y Lucrecia Maupomé (eds.). México: Universidad Nacional Autónoma de México, Instituto de Investigaciones Históricas (Serie de Historia de la Ciencia y la Tecnología, 4), 153161.

Navarijo Ornelas, María de Lourdes

1996 "La presencia de las aves en la pintura mural teotihuacana", La pintura mural prehispánica en México: Teotihuacan, vol. 1, t. II Estudios. Beatriz de la Fuente (coord.). México: Universidad Nacional Autónoma de México, Instituto de Investigaciones Estéticas, 325-341. 
Navarijo Ornelas, María de Lourdes

1999 "Análisis de representación faunística en una muestra de vasijas mayas del Clásico", Suplemento del Seminario Permanente de Iconografía, 2: 1-19. México: Instituto Nacional de Antropología e Historia, Dirección de Etnología y Antropología Social.

2000 "Arte y Ciencia a través de las imágenes de aves en la pintura mural prehispánica”. Anales Instituto de Investigaciones Estéticas, XXII (77): 5 -32, otoño. México: Universidad Nacional Autónoma de México.

2001 "Las aves en el mundo maya prehispánico", La pintura mural prehispánica en México: Área Maya, vol. II, t. III. Estudios. Beatriz de la Fuente (dir.) y Leticia Staines (coord.). México: Universidad Nacional Autónoma de México, Instituto de Investigaciones Estéticas, 221-253.

2008 "Las aves en los contextos funerarios”, La pintura mural prehispánica en México: Oaxaca, vol. III, t. III. Estudios: Beatriz de la Fuente, Verónica Hernández Díaz y Ena Lastra (eds.). México: Universidad Nacional Autónoma de México, Instituto de Investigaciones Estéticas, 245-283.

Niederberger, Christine

1996 "Paisajes, economía de subsistencia y agrosistemas", Temas Mesoamericanos. Sonia Lombardo y Enrique Nalda (coords.). México: Instituto Nacional de Antropología e Historia / Consejo Nacional para la Cultura y las Artes, 1150 .

Peterson, Roger Tory y Edward L. Chalif

1989 Aves de México. Guía de Campo. México: Diana.

Polaco, Oscar J.

1986 "Los murales: una perspectiva biológica", El lugar donde muere la lluvia en la tierra Cacaxtla. Sonia Lombardo de Ruiz, Diana López de Molina, Daniel Molina Feal, Carolyn Baus de Czitrom y Oscar Polaco. Tlaxcala: Secretaria de Educación Pública / Instituto Nacional de Antropología e Historia / Gobierno del Estado de Tlaxcala / Instituto Tlaxcalteca de la Cultura, apéndice 4, 531-536.

Sahagún, fray Bernardino de

1969 Historia general de las cosas de Nueva España. Tomo I. 2a edición, con numeración, anotaciones y apéndice de Ángel María Garibay K. México: Porrúa (Biblioteca Porrúa, 8).

Secretaría del Medio Ambiente y Recursos Naturales (Semarnat)

2010 "Norma Oficial Mexicana NOM-059-ECOL. Protección ambiental, especies nativas de México de flora y fauna silvestres, categorías de riesgo y especificaciones para su inclusión, exclusión o cambio. Lista de especies en Riesgo". Diario Oficial. México: jueves 30 de diciembre del 2010.

Seler, Eduard

2004 Las imágenes de animales en los manuscritos mexicanos y mayas. Traducción Joachim von Mentz. Brigida von Mentz (ed. y est. prel.). México: Casa Juan Pablos, Centro Cultural. 
